\title{
Roteiro turístico e experiência: uma análise técnico operacional do guiamento e da interpretação patrimonial no programa "olha! Recife"
}

Itinerary tours and experience: a technical analysis on the patrimonial interpretation and guidance on "Olha Recife" program

\section{Rebecca Cisne}

Faculdade de Comunicação Tecnologia e Turismo - Facottur - Olinda - Pernambuco - Brasil

\section{Darcilene Guggelberger}

Faculdade de Comunicação Tecnologia e Turismo - Facottur - Olinda - Pernambuco - Brasil

\section{Dione Esteves}

Faculdade de Comunicação Tecnologia e Turismo - Facottur - Olinda - Pernambuco - Brasil

\begin{abstract}
Resumo: Esta pesquisa tem como objetivo analisar os guiamentos nos roteiros do programa "Olha! Recife", a luz do funcionalismo, destacando as categorias tradicionais (funções manifestas) e contemporâneas (funções latentes) do guiamento e da interpretação patrimonial, para que possa saber se o guiamento realizado durante os roteiros turísticos do programa "Olha! Recife" considera as necessidades contemporâneas do Turismo quando da interpretação patrimonial atuando como mapas cognitivos do texto urbano permitindo a geração de experiência marcante para o turista cidadão. A coleta de dados foi feita por meio de observação sistematizada nas modalidades a pé e de ônibus do programa. Os resultados revelam que os guias têm competências técnicas e comportamentais tradicionalmente esperadas, mas ainda precisam ter mais aprimoramento das competências técnicas de interpretação patrimonial para que se possa resultar em lugarização do turista-cidadão.
\end{abstract}

Palavras-chave: Roteiro Turístico. Guiamento. Lugarização. Experiência. Olha! Recife.

Abstract: This research aims to analyse the technique of the tourist guides along the tours of the project "Olha! Recife" in the lights of functionalism. For this end we highlighted the traditional categories (manifested functions) and the contemporary categories (latent functions) of the guide techniques and the patrimonial interpretation, in order to know if the guidance given along with the tours of this project takes into account the actual needs of the Tourism in relation to the patrimonial interpretation acting as cognitive maps of the urban text leading to an highlighted experience to the citizens tourists. The data were collected through systematized observation. The results show that the tourist guides got the technical and behaval competences traditional expected, but sill lack on regarding to the technical competences on the patrimonial interpretation in order to lead to the "placement" of the citizen tourist.

Keywords: Itnerary tours. Tourist Guidance. Placement. Experience. Olha! Recife. 


\section{Introdução}

Este estudo emerge frente as inquietações epistemológicas acerca do Turismo e a necessidade hodierna de pensar este campo sobre o viés da complexpara além do pragmatismo vigente. Propõese, então, refletir sobre Turismo a partir do programa "Olha! Recife", com base nas seguintes categorias de análise: roteiro turístico, guiamento, interpretação patrimonial e experiência. Frente a isto coloca-se a seguinte problemática: o guiamento realizado durante os roteiros turísticos do programa "Olha! Recife" considera as necessidades contemporâneas do Turismo quando da interpretação patrimonial atuando como mapas cognitivos do texto urbano permitindo a geração de experiência marcante para o turista cidadão? Para tanto se propõe como objetivo analisar o guiamento durante os roteiros do programa "Olha! Recife" sob uma abordagem aproximada ao funcionalismo, elucidando as funções manifestas e latentes das categorias analíticas já apresentadas.

O programa "Olha! Recife", vinculado à Secretaria de Turismo e Lazer de Recife, surgiu para sensibilização turística da população da cidade e, assim, consiste em levar à sociedade uma nova forma de lazer, agregada à oportunidade de obter um novo olhar sobre a cidade. Os objetivos do programa são: elevar o sentimento de pertencimento da sociedade e autoestima; e promover novas ideias e posturas sociais de valorização das tradições socioculturais e da vocação turística de Recife.

O programa é integrado por quatro seguimentos: a) "Olha! Recife a Pé", com 51 roteiros; b) "Olha! Recife de Ônibus", com 58 roteiros; c) "Olha! Recife do Rio", com 04 roteiros; e, finalmente, d) "Olha! Recife Pedalando", com 31 roteiros. Todos os passeios são gratuitos e as inscrições são feitas pelo site do programa. Em todas as modalidades os turistas são acompanhados por um guia de turismo e um funcionário da Secretaria de Turismo, que coordena as atividades do dia.

O corpus desta investigação é composto por sete roteiros de duas modalidades (a pé e de ônibus), feitos no período de 08 de novembro de 2015 a 12 de março de 2016, conforme ilustra no quadro 1.

Quadro 1: cronograma de visita de campo

\begin{tabular}{|c|c|c|l|c|}
\hline Data & Horário & Modalidade & Tema & Guiamento \\
\hline 08/11/15 & $\begin{array}{c}09: 00- \\
11: 00\end{array}$ & A pé & $\begin{array}{l}\text { Casa } \\
\text { Amarela }\end{array}$ & Guia 01 \\
\hline $14 / 11 / 15$ & $\begin{array}{l}14: 00- \\
17: 00\end{array}$ & De ônibus & $\begin{array}{l}\text { Roteiro } \\
\text { Literário: } \\
\text { Solano } \\
\text { Trindade }\end{array}$ & Guia 02 \\
\hline $21 / 11 / 15$ & $\begin{array}{c}14: 00- \\
17: 00\end{array}$ & De ônibus & $\begin{array}{l}\text { Circuito } \\
\text { Afro }\end{array}$ & Guia 01 \\
\hline $22 / 11 / 15$ & $\begin{array}{c}09: 00- \\
11: 00\end{array}$ & A pé & $\begin{array}{l}\text { Recife } \\
\text { Afro: } \\
\text { Poesias, } \\
\text { lutas } \\
\text { canções }\end{array}$ & Guia 03 \\
\hline $20 / 12 / 15$ & $\begin{array}{c}09: 00- \\
11: 00\end{array}$ & A pé & $\begin{array}{l}\text { Cemitério } \\
\text { Santo } \\
\text { Amaro }\end{array}$ & Guia 01 \\
\hline 27/02/16 & $\begin{array}{l}13: 00- \\
15: 30\end{array}$ & De ônibus & $\begin{array}{l}\text { Jardim } \\
\text { Botânico }\end{array}$ & Guia 04 \\
\hline $12 / 03 / 16$ & $\begin{array}{c}14: 00- \\
17: 00\end{array}$ & De ônibus & $\begin{array}{l}\text { Recife e } \\
\text { Olinda }\end{array}$ & Guia 05 \\
\hline
\end{tabular}

Fonte: As autoras.

Para a coleta de dados utilizou-se um formulário que, segundo Marconi e Lakatos (2010), é um dos instrumentos essenciais para a investigação social, cujo sistema de coleta de dados consiste em obter informações diretamente do entrevistado. A escolha da aplicação do formulário foi para o alcance do resultado desta pesquisa, a qual contribuiu de maneira positiva dos resultados, pois, conforme as autoras, este instrumento permite a adaptação ao objeto de investigação, aos meios que se possui para realizar o trabalho e a precisão das informações em um grau de exatidão suficiente e satisfatório para o objetivo proposto. Os critérios que utilizamos para elaboração do formulário foram divididas em 5 seções, sendo elas roteiro turístico tradicional (8 pontos observáveis), tematização (4 pontos observáveis), roteiro turístico pós-moderno (5 pontos observáveis), guiamento (16 pontos observáveis) e interpretação patrimonial (8 observáveis), totalizando 41 pontos observáveis.

Complementarmente aos formulários foram realizadas entrevistas em grupo focal, onde os sujeitos da pesquisa expressaram suas vivências nos roteiros. A entrevista foi do tipo estruturada, com 10 perguntas que buscavam narrativas das experiências 
vivenciadas pelos turistas, que relataram sobre suas expectativas, sensações, emoções e sentimentos ao participarem dos roteiros do programa. Optou-se pelo grupo focal, pois se julgou ser a maneira mais eficaz para se coletar os registros acerca das experiências vivenciadas pelos turistas. Durante a visitação, aqueles sujeitos que se mostraram mais ativos na visitação foram convidados a participar do grupo ao término do roteiro.

Para a construção desta investigação, metodologicamente, valeu-se de uma aproximação ao método funcionalista, conforme proposto por Malinowski. Marconi e Lakatos (2010, p. 92) afirmam que a rigor este é "mais um método de interpretação do que de investigação". Nesta abordagem busca-se descrever as funções do guiamento e da interpretação patrimonial para (e nos) roteiros turísticos desenvolvidos no programa "Olha! Recife", a fim de identificá-las como mapas cognitivos do texto urbano, que permitam uma melhor comunicação entre a cidade e o turista. Assim, estudou-se o roteiro turístico do ponto de vista da função de suas unidades, isto é, como um sistema organizado de atividades.

Merton (apud MARCONI \& LAKATOS, 2010) propõe os conceitos de funções manifestas e funções latentes. Aquelas têm finalidades pretendidas e esperadas das organizações, e estas são denominadas como não esperadas e inclusive não reconhecidas. Nesta investigação, as funções manifestas estão vinculadas ao modelo e roteirização tradicional, conforme ideias de roteiro turístico proposto por Tavares (2002) e Bahl (2004). Já as funções latentes estão relacionadas ao modelo de roteiro turístico pós-moderno, de acorcom com Cisne (2010).

\section{Roteiro turístico: instrumento para leitura do espaço urbano}

Os roteiros turísticos são importantes instrumentos para o desenvolvimento da atividade turística, pois são eles que possibilitam ao visitante um conhecimento mais amplo, organizado ou temático dos pontos de interesse turístico do destino (TAVARES, 2002).

Cisne (2010) considera que o termo roteiro turístico é polissêmico e ainda pouco discutido sob o ponto de vista conceitual. Segundo ela os autores que se dedicam a esse estudo apontam para o roteiro como sendo a indicação de uma sequência de atrativos merecedores de serem visitados durante a atividade turística (TAVARES, 2002; BAHL, 2004).

Para o Ministério do Turismo (BRASIL, 2007) o roteiro turístico é sinônimo de itinerário, suas características se dão pela equação de elementos que the conferem identidade. Ainda segundo o órgão federal, o objetivo do roteiro é garantir o planejamento, a gestão, a promoção e a comercialização turística dos destinos/atrativos que integram o roteiro. Ainda se pode dizer que "a roteirização confere realidade turística aos atrativos que estão dispersos através de sua integração e organização" (BRASIL, 2007, p. 15).

Apesar do pragmatismo mercadológico na discussão acerca do tema, Cisne (2010, p. 366) considera que

o Roteiro Turístico tem uma realidade per ser, inerente à sua materialização. Isoladamente, sob o olhar pragmático, ele assume valor de mercado, mas não se pode esquecer que, frente às novas sensibilidades de Sujeitos que navegam pela era da tecnologia da informação, o Roteiro Turístico é dotado também de um valor social, intrínseco a sua existência relacional. [grifo nosso]

Para ela, é necessário que se divida o entendimento de roteiro turístico a partir de duas classificações: o roteiro turístico tradicional e o roteiro turístico pós-moderno. A diferença entre ambos poderia ser explicada pelo fato de que o roteiro turístico pós-moderno "tem autonomia em sua existência, por sua essência corpórea, diferentemente do Roteiro Turístico Tradicional que não tem autonomia de significação" (CISNE, 2010, p. 366).

Outro fator que delineia a diferença entre ambos é que o

roteiro Turístico pós-moderno, dá margens ao imprevisto, pois abre espaço à processos que 
são negados no roteiro tradicional, cujo foco está em assegurar a incidência do acontecer. $O$ roteiro turístico pós-moderno assume a possível mudança das funções das coisas. Essa migração de valores não é aleatória. Ela revela as determinações pelas quais o roteiro tradicional busca encaixar-se nas formas preexistentes e criadas, podendo somente ser entendido como um modelo espaço-temporal (CISNE, 2010, p. 367).

De acordo com Castells (1999) tempo e espaço são categorias essenciais da existência humana. Portanto não é de se estranhar a concepção de roteiro turístico tradicional considere estas duas categorias como fundantes de seu conceito, o que apesar de verdadeiro não pode ser limitante. É com base nisso que Cisne (2010) propõe ampliar a compreensão de roteiro turístico pensando tempo e espaço de maneira abstrata (sensitiva) e considerando também a subjetividade e o sujeito como categorias do roteiro turístico pós-moderno.

É com base nessa ideia que o mote da discussão da autora está voltado à experiência que pode ser vivida através do roteiro turístico. Ou seja, os eventos e o valor social que constituem o roteiro são fundamentais para atribuir a ele a característica de pós-moderno (CISNE, 2010).

Sob essa perspectiva o roteiro turístico está intrinsicamente correlacionado à intepretação da cidade enquanto texto. Com base em Jameson, Gastal (2006, p. 19) apresenta a interpretação

\begin{abstract}
como ato alegórico de reescrever um determinado texto como um ato interpretativo específico, não como resultado de um fluxo de percepções, mas sim uma experiência combinatória cujo fechamento se dá no momento em que todas as permutas finalmente se esgotam, ou seja, quando todas as possibilidades sugeridas pelo texto na sua intertextualidade tenha sido realizada.
\end{abstract}

A intertextualidade é um fator fundamental à leitura do espaço urbano. Ela refere-se a uma estratégia de mistura não só de conteúdo, mas de aspectos formais da obra, sem que se destruam mutualmente, ou seja, é a presença ou a passagem de um significante a outro (GASTAL, 2006). A partir disso, entende-se a cidade como um texto aberto e instigante para o leitor (turista) que busca no guia de turismo as possibilidades de interpretação das contingências intertextuais, ou seja, a compreensão de todos os contextos: histórico, social, econômico, cultural, etc. Conclui-se, então que o pós-turista, o caçador de experiências construídas pelo deslocamento, pela fuga da rotina e pelo estranhamento, não está em busca de apenas um conteúdo, mas de uma mistura de vários textos em um só, sem que se destruam mutualmente.

Dessa forma, o roteiro turístico pós-moderno configura-se como instrumento de leitura dos contextos social, político e econômico do lugar, vinculados aos fatos históricos dos atrativos e aos aspectos psicológicos das percepções do turista sobre o destino visitado.

Cisne (2010) explica que o roteiro turístico pósmoderno

orienta o fluxo turístico, indicando caminhos e propondo, por meio da subjetividade, emoção e percepção de cada Sujeito que o realiza, atividades a serem vivenciadas ao longo do espaço físico percorrendo seus significados, atribuindo ao espaço, o sentido e o valor de Lugar (CISNE, 2010, p. 195). [grifo nosso]

Portanto, para que se possa analisar o guiamento em roteiros turísticos à luz da pósmodernidade faz-se necessário que se discutam categorias como experiência e interpretação patrimonial.

\section{Guiamento e interpretação patrimonial: construindo mapas cognitivos sobre a cidade}

Souza (apud CHIMENTI \& TAVARES, 2007, p.18) explica que "o guia de turismo é o profissional apto a prestar informações sobre o local visitado e assessorar o turista quando necessário". As autoras destacam algumas características são essenciais para o bom guia de turismo: a) Habilidade em relacionar-se bem com pessoas e grupos; b) Ter agilidade, ser dinâmico, pensar rápido e ter aptidão para solucionar imprevisto; c) Dominar os princípios da psicologia interpessoal, ter diplomacia e possuir autoridade na medida certa; d) Saber trabalhar em 
equipe, pois o guia precisará de apoio em diversas áreas.

Segundo Carvalho (apud CHIMENTI \& TAVARES, 2007, p. 29) para exercer bem suas funções, o guia de turismo necessitará dominar três principais áreas de conhecimento: Conhecimento técnico, noções sobre habilidades nas relações interpessoais e conhecimentos gerais.

Tradicionalmente considera-se que para que um guia de turismo ofereça serviços de qualidade é necessário muito mais que o cumprimento de suas funções com eficiência. Demanda-se que ele esteja atento ao turista, pronto para ajudar sempre que é necessário, apto a prever problemas para resolvê-los imediatamente, de preferência, antes mesmo que os turistas o percebam (CHIMENTI \& TAVARES, 2007).

Há também aspectos éticos que precisam ser observados, como o respeito às diferenças (seja de gênero, idades, religião); não se pode esquecer, porém, que "ao guia cabe não apenas a responsabilidade de não fazer discriminações, mas também não permitir que estas sejam feitas por terceiros" (CHIMENTI \& TAVARES, 2007, p. 34). Ainda no que se referem às questões éticas, as autoras também apontam que um profissional não deve comentar ou depreciar a capacidade de trabalho de colegas, estando estes ou não realizando serviços paralelos ou em parceria.

A comunicação e o dinamismo também são competências comportamentais importantes. A comunicação tanto verbal quanto corporal são essenciais para o sucesso de seu trabalho. Com base em Teixeira, Chimenti e Tavares (2007, p. 133) apontam para oito princípios básicos da boa comunicação: "clareza, coerência, adequação, oportunidade, distribuição, essencialidade, interesse e aceitação". Isso significa que o guia precisa ter cuidado com o tom de voz, para que desperte o interesse do público, variando a entonação em seu tempo. Falar sem pausar e variar a entonação tornase cansativo causando desinteresse nos turistas para as informações que estão sendo passada sobre o atrativo. Os autores explicam que o guia de turismo deverá estruturar as informações, organizando a história do lugar em uma narrativa coesa e coerente, cujo enredo tenha uma sequência lógica e perceptível aos turistas (CHIMENTI \& TAVARES, 2007).

Além disso, o guia de turismo precisa conhecer o perfil de cada integrante do grupo, pois isso fará com que ele execute suas atividades de forma eficiente, coerente, com clareza e que passe confiança para o turista.

No entanto, quando se trata de guiamento em roteiros turísticos pós-modernos exigem-se do guia de turismo muito mais que essas competências ${ }^{1}$ técnicas e comportamentais. Nesse novo cenário é necessário que o guia seja capaz de interpretar o patrimônio, analisando o espaço turístico visitado, levando à lugarização temporária (entre-lugarização) do turista no espaço, gerando experiências positivas e marcantes.

Castrogiovanni (2007) constrói a noção de entre-lugar no turismo, a partir da ideia de Augé de não lugar, e da ideia de lugar na geografia. $O$ autor explica que o não-lugar "parece ser a simples negação do lugar. O lugar e o não-lugar são, antes, polaridades fugidias: o primeiro não [pode] ser completamente apagado e o segundo nunca se realiza totalmente". (CASTROGIOVANNI, 2007, p. 6). O autor diferencia estas duas categorias pelo seu processo de constituição, ambas são frutos de construções sociais, porém, o não-lugar é a medida da época. O autor conclui que o entre-lugar é portanto, o lugar praticado pelo turista durante a viagem. Nas palavras dele, o entre-lugar turístico é

a lugarização do espaço geográfico substanciada pelo sujeito visitante na dialogicidade estabelecida entre o seu lugar (lugar conhecido) e o lugar/não-lugar visitado (desconhecido). Ele é simbólico, enquanto existência, mas possui uma densidade representativa, a partir da cultura (CASTROGIOVANNI, 2007, p. 6).

Para que isso aconteça cabe ao guia promover a interpretação do texto urbano, revelando seus signos e significados através da intertextualidade urbana, conforme já explicitado anteriormente, pois "a

\footnotetext{
${ }^{1}$ Para fins de análise deste estudo, considera-se competência 0 conjunto articulado de conhecimentos, habilidades e atitudes.
} 
cidade é um discurso, e esse discurso é verdadeiramente uma linguagem: a cidade fala aos seus habitantes, nós falamos à nossa cidade, a cidade onde nos encontramos simplesmente quando a habitamos, a percorremos, a olhamos [...]" (BARTHES apud GASTAL, 2006, p. 71).

Dentro desse contexto, a cidade (do cidadão ou para o forasteiro) emite mensagens, transmite informações e conteúdo, o que faz com que uma teia cada vez mais complexa seja tecida em torno do Turismo. Para facilitar esta comunicação, guias turísticos e de turismo emergiram no mercado de viagens e turismo. No entanto é necessário um novo olhar sobre esta tessitura, que transcenda a tradicional visão do guia de turismo com a função de apresentar os pontos turísticos da cidade; a experiência passa a ser produto essencial do pósturismo, impondo ao guia de turismo uma visão multidisciplinar sobre a cidade e igualmente sobre o turismo enquanto campo de estudo e de atuação profissional.

Essa mudança demanda dos guias de turismo entender a cidade não mais como um aglomerado urbano de prédios e monumentos, cronologicamente organizados naquilo que se chama de "roteiro turístico"; mais do que isso, o guia deve ser capaz de construir sentidos, e tecer significados passíveis de interpretação e semiose.

Nesse cenário, o bom guia é aquele capaz de ler, falar e transcrever para o turista a linguagem da cidade sem metáforas, de modo a promover para o sujeito turístico incorporações tempo-espaciais do lugar. Assim, este profissional deve trabalhar a partir do nível de significado de forma a aproximar o sujeito turístico em uma relação com o espaço geográfico e turístico promovendo a significação para transformar este espaço em um lugar provisório do turista (entrelugarizando-o)

Assim, o guia deve assumir um ato interpretativo específico, conforme elucidado anteriormente, de modo a gerar uma narrativa visual, pois segundo Gastal (2006), o espaço urbano é sujeito a uma leitura semiótica dentro de suas práticas, manifestações, jogos próprios e superfícies, tornando-se com isso um texto. Assim, o guia deve se valer da interpretação do patrimônio para estimular o olhar e determinar o turista como um expectador ativo. Cabe, então, a este profissional compreender a cidade "como um texto a ser decifrado não apenas pelos visitantes, mas pelos próprios moradores que, não raro sentem-se perplexos ante o emaranhado de ruas, bairros [...]" da cidade. (GASTAL, 2006, p. 0910)

Essa compreensão leva a entender Turismo de forma muito mais abrangente; considerando que o cidadão pode assumir a postura e identidade de turista mesmo na cidade onde reside, torando-se assim, um turista-cidadão ${ }^{2}$. Sob este ponto de vista, tempo e espaço deixam de ser as únicas categorias norteadoras para o entendimento de Turismo, abrindo-se espaço para as categorias estranhamento ${ }^{3}$ (GASTAL \& MOESCH, 2007) e fuga das rotinas espaço temporais (GASTAL, 2005).

Tendo exposto isso, parece emergente questionar como sentidos podem ser construídos em contextos urbanos, a partir da compreensão da cidade como um texto. Gastal (2006) vale-se da ideia de mapas cognitivos proposto por Lynch, para explicar estes como instrumentos para descrever como as pessoas constroem sentidos de seus contextos urbanos. A autora explica que "o sentido nasce de uma interseção do pessoal e do social, que capacita as pessoas a funcionarem nos espaços urbanos nos quais se movem" (p. 22). A autora conclui que é por meio do mapeamento cognitivo que se pode chegar às "questões ocultas" da cidade.

Desse modo, entender o turismo como um processo comunicativo em que a cidade assume a posição de texto e o turista a condição de leitor, impõe a necessidade de compreender que o

leitor é uma posição a ser preenchida dentro do texto, num processo de geração de

\footnotetext{
2 Segundo Gastal e Moesch (2007, p. 60) o turista cidadão é o "sujeito que entendeu os fixos e precisa apropriar-se dos fluxos, neles compreendida a sua própria situação de sujeito em trânsito, para nela colocar subjetividade, aprendendo a expressá-la no mundo".

${ }^{3}$ Metodologia que implica em "incentivar a leitura do não-verbal como uma estratégia de destruição, na cidade, do seu sistema de ordem, estabelecido ante olhares sem inquietação" (GASTAL \& MOESCH, 2007, p. 60-1).
} 
sentido, que envolveria também o contexto [...]. No contexto enunciativo estará o locus do sentido, não mais pura e simplesmente centrado no autor, no texto ou mesmo no leitor, isolados, descontextualizados. (GASTAL, 2006, p. 46).

\section{Experiência: valor agregado ao produto turístico}

A ideia de experiência tem sido cada vez mais debatida atualmente no cenário da produção do saber turístico. Mesmo assim, ainda se tem uma lacuna a ser preenchida nesse âmbito.

A práxis e o pragmatismo que têm acompanhado 0 desenvolvimento da atividade turística no Brasil e, consequentemente, a produção de conhecimento sobre turismo tem enfatizado a viagem como um deslocamento geográfico, cultural ou social. No entanto, Trigo (2010) aponta que as viagens devem também ser compreendidas como uma jornada interior, como uma experiência fundamental na vida das pessoas. Na visão do autor, as viagens épicas seriam matrizes das experiências que em geral as viagens gostariam de proporcionar, exclusivamente no imaginário comercial turístico de massa.

O autor complementa que a experiência é primordial para a socialização, o aprendizado, a articulação profissional e a satisfação pessoal e, a partir de Blackburn, o autor explica que

\begin{abstract}
a experiência possui conteúdos importantes. É o mundo em si, que nos é representado, e o modo que encaramos e vivemos o mundo é manifesto por nossas palavras e atitudes. 0 relacionamento com a própria experiência envolve memória, reconhecimento e descrição, todos aprendidos por habilidades exercidas nas relações interpessoais, seja em grupo, mais restrito, seja, na sociedade (BLACKBURN apud TRIGO, 2010, p. 26).
\end{abstract}

Toda viagem é experiência, mas nem toda viagem é uma experiência que mereça ser repetida ou que marque significativamente a vida de alguém (TRIGO, 2010). Portanto, é importante esclarecer que para ser uma experiência marcante, a viagem deve transcender a banalidade e a trivialidade estereotipadas e convencionais, de modo a se organizar como uma experiência que nasça de uma virtude pessoal do viajante à procura de momentos e lugares que enriqueçam sua história (TRIGO, 2010).

A experiência se constrói no nível mental, psicológico do sujeito; a compreensão, portanto, das funções mentais superiores é necessária quando se quer entender de que forma uma experiência significativamente marcante se constrói para o sujeito.

A base que fundamenta isto é a sensação. MerleauPonty (apud PANOSSO, 2010, p. 47) diz que "a sensação é dada ao homem somente por sua relação com o objeto externo".

A experiência tem a ver com a construção de significados pelo sujeito ao que foi vivido:

A experiência que se busca é uma passagem individual, um esforço multissensorial que envolve tanto os sentidos da pessoa que busca experiência, quanto a presença, o recorte da temporalidade e dos sentidos da sua existência [...] Assim se envolve os sentidos, o imaginário, a temporalidade, a corporeidade (MACIEL, 2010, p. 66).

Fundamentado no que fora exposto até então, vê-se que a compreensão acerca das funções do guia de turismo para atuação no mercado hodierno devem ser ampliadas de modo que maior atenção seja dada nos aspectos de leitura espacial e interpretação patrimonial para que experiências marcantes possam ser geradas a partir da visitação. Afinal, "o turista não quer ser um expectador passivo em sua viagem; ele quer vivenciar sensações. O turista de hoje quer ter a sensação de que viveu um momento único, marcante, inesquecível" (GAETA, 2010, p. 140). O diferencial na atuação do guia de turismo estará no valor perceptível, que proporcione "sensações ímpares que diferenciem uns itens dos outros, permitam a seleção e aquisição a partir de necessidades individuais" (GAETA, 2010, p. 140).

Essa mudança na atuação do guia de turismo está calcada naquilo que Molina (2003) aponta como o pós-turismo, ou seja, o turista passa a ser um colecionador de experiências e pode visitar o mesmo destino mais de uma vez se este o proporcionar experiências diferentes. 


\section{Análise de dados: o caso do programa "Olha! Recife"}

\subsection{Roteiro Casa Amarela}

No roteiro "Casa Amarela" observou-se que os turistas se sentiam motivados e curiosos em relação ao bairro, neste cenário surgiram indagações sobre os pontos citados (o América Football Club, a mercearia Nabuco, o mercado de casa amarela, a conversão dos bondes próximo ao mercado, o que deu o nome a outro bairro, o bairro do entroncamento), o guia expôs as informações e apresentou o imóvel que deu origem ao nome do bairro. Neste roteiro não houve ocasiões nas quais 0 turista necessitasse ser assessorado, assim como também não houve nenhuma ocorrência de imprevisto.

O guia 01 atendeu aos procedimentos necessários à técnica de guiamento, teve nitidez em sua eloquência e proporcionou uma experiência de leitura da realidade sócio-histórica do bairro, levando o grupo a conhecer mais o lugar, transcendendo a obviedade turística do que é visitado naquela região, o que culminou no processo interpretativo, na avidez dos turistas em conhecer o bairro através dos atrativos, uma vez dispersos, que ao terem sido reunidos construíram significados ao bairro, possibilitando ao turista ter uma visão ampla do espaço transcorrido. A abertura feita pelo guia à participação causou um despertar dos turistas para o trajeto que foi realizado, isso possibilitou também a identificação de uma das funções latentes: a inserção do turista no processo de comunicação pessoal e social.

Outras funções latentes também puderam ser identificadas nesse roteiro: o mapeamento cognitivo para revelação das "questões ocultas da cidade" e a leitura e transcrição da linguagem da cidade sem metáforas, fomentado pela revelação aos turistas do imóvel que dá nome ao bairro e que alimenta em muito o imaginário coletivo sobre o lugar. Muitos dos turistas acreditavam que o nome "Casa Amarela" advinha do mercado; suposição feita pela importância deste para o bairro; quanto a este fato, no grupo focal, na narrativa sobre a experiência, ficou marcada no discurso dos sujeitos a aprendizagem e o conhecimento, apesar disso, durante a entrevista os sujeitos não demonstraram nenhum sinal de que esta tenha sido uma experiência marcante. Cabe ressaltar, porém, que o conhecimento e aprendizagem não se limitaram ao desvelar do imóvel que batiza o bairro: "Super interessante [essa experiência] do ponto de vista de melhor conhecer a cidade [...] você não só morar na cidade, mas realmente conhecer, saber de onde as coisas vêm" (sujeito 01); este trecho do discurso de um dos participantes reforça a ideia apresentada de Gastal (2005) sobre Turista-cidadão como aquele eu foge das suas rotinas espaço temporais, que conhece a cidade onde mora e nela desperta o olhar para os atrativos e monumentos.

Sabendo que a experiência se constitui a partir das sensações e estas são calcadas na percepção, pode-se afirmar, com base na entrevista do grupo focal que a percepção dos turistas foi marcada pelo olhar: "hoje creio que todo mundo que compareceu a esse passeio, quando passar por Casa Amarela de novo, vai olhar com outros olhos [...]" (sujeito 01). Com base nisso é possível inferir que o conhecimento da história, a partir da observação dos marcos no cotidiano, parece ser bastante significativo e empolgante àquele que aprende, pois com a visitação pode-se ter "uma percepção totalmente mais ampla do que tinha originalmente, hoje passamos por regiões e locais e que muita gente não sabia como foi criado, como foi nascido [...]" [sic] (sujeito 01) "E também porque é instigante [...] é lógico que não tem como saber a história toda do bairro, da região, da cidade, mas você acaba estimulado a pesquisar a respeito disso, você desperta mais para buscar o conhecimento." (sujeito 03).

Estes relatos corroboram à observação feita quanto à promoção da interpretação do texto urbano e a habilidade do guia 01 em construir sentidos e a elaboração de significados passivos de interpretação e semiose, como função latente, pela atribuição de significado aos fatos históricos e sociais antes ignorados ou pouco conhecidos pelo grupo. 
Ainda no que se refere à experiência narrada pelos sujeitos, ficou clara a emoção resultante do roteiro: afetividade pela cidade, indicada em relatos como: "[...] a sensação de descoberta [...] mesmo que não seja daqui, dá um sentimento de pertencimento do local, de identidade do local" (sujeito 03); "olhar a cidade que você mora com outros olhos" (sujeito 01). Assim, o sentimento que emerge é 0 de pertencimento à cidade.

\subsection{Roteiro Recife Afro: poesias, lutas e canções}

O roteiro "Recife Afro: poesias, lutas e canções" proporcionou um olhar diferente aos atrativos visitados, a partir do conhecimento do contexto histórico referente à temática; disso emergiu nos turistas uma sensação de pertencimento à cidade, despertando-lhes um olhar de turista, conforme pode-se ser visto quando um dos sujeitos afirma que "você sai andando na cidade, sem ser turista, no dia a dia, você vai ver lojas, restaurantes e aqui você vê a História" (sujeito 05). A organização dos atrativos no espaço da cidade, a partir de sua contextualização histórica, favoreceu a apreciação e a descoberta do novo levando à satisfação e ao enriquecimento pessoal. O guia 03 fugiu do tema do roteiro várias vezes, dando mais ênfase à história da cidade de Recife, do que à tematização proposta, mas atendeu aos princípios da psicologia interpessoal. $\mathrm{O}$ profissional demonstrou conhecimento das técnicas de guiamento e manteve o grupo coeso.

Em relação à interpretação patrimonial, o profissional despertou a curiosidade dos turistas, inspirando-os a novas atitudes, fomentando também a compreensão e a apreciação do destino visitado, pela narrativa histórica: "eu não sabia a fundo a história e descobri um monte de coisas com esse passeio" [sic] (sujeito 07), mas ainda assim, não houveram indícios nos relatos dos participantes de que esta tenha sido uma experiência marcante. Por outro lado, ainda quanto à interpretação, deixou de revelar o significado dos signos do lugar, de despertar emoções dos turistas, de entretê-los e também não demonstrou sinais de envolvimento da população local no processo interpretativo.

Concernente à percepção vê-se, novamente, a marca do olhar: "eu acho que agora sempre que passar por um lugar que a gente entende a história, vai olhar de um jeito diferente" (sujeito 08).

Esse roteiro também apresentou uma categoria latente ao mostrar uma visão multidisciplinar sobre a cidade. É importante que seja ratificado que esta visão somente foi possível pelo fato de o guia ter fugido do tema, apresentado aspectos socioeconômicos e geográficos da cidade, com estas informações os turistas foram envolvidos por um despertar sobre o conhecimento da história do lugar, o que resultou em uma sequência organizada dos elementos históricos apresentados, proporcionando um conhecimento mais amplo. Devido à narrativa da história da cidade, o guia construiu sentidos e elaborou significados passivos de interpretação, ainda que não tenha revelado os signos do lugar, conforme já exposto anteriormente.

\subsection{Roteiro Cemitério de Santo Amaro}

O roteiro que aconteceu no Cemitério de Santo Amaro proporcionou um vislumbre de aspectos artísticos e arquitetônicos: "foi muito bom para poder observar todas as esculturas de arte cemiterial, que admiro [...] é muito interessante conhecer todos os aspectos da arte, as diferenças de nacionalidade dos aspectos artísticos das obras [...]" (sujeito 11). Pelo tema proposto, foi um roteiro incomum no qual os turistas apreciaram os monumentos dos túmulos e desmistificaram a visão de que o cemitério é um lugar "macabro", pois a visitação ao cemitério "tira esse receio que se tem do cemitério, e ver essa parte cultural" (sujeito 13). Neste roteiro, o guia revelou os signos do lugar em muitos desses jazigos, fugindo do senso comum e agregando conhecimento de fatos até então desconhecido pelo grupo. Apesar disso, as expectativas, embora tenham sido alcançadas, não foram superadas: "Eu já imaginava isso, nada de diferente [...]" (sujeito 13). 
O guia 01, além de despertar curiosidades sobre fatos ignorados pelos turistas, atendeu aos procedimentos de técnica de guiamento e demonstrou domínio do destino visitado. A aproximação ao processo interpretativo se deu através da narrativa de curiosidade sobre o lugar, mas os turistas não indicaram (nem quando questionados diretamente, tampouco pode-se perceber nas respostas a outras questões) a presença de emoções que justificasse que esta fosse uma experiência marcante. Referente aos sentimentos o sujeito 12 afirmou ter emergido sentimentos de paz, tranquilidade e harmonia, ao passo que o sujeito 13 apontou para o medo.

Pela fuga do senso comum, percebeu-se como função latente a inserção do turista no processo de comunicação pessoal e social por meio da interpretação, possível pela desmistificação do cemitério e pela ampliação dos conhecimentos históricos e sociais dos turistas acerca da cidade, a partir, das artes e arquiteturas dos atrativos visitados.

\subsection{Roteiro literário: Solano Trindade}

O "Roteiro Literário: Solano Trindade" teve como ponto alto a peça teatral apresentada na Academia Pernambucana de Letras, que destacou algumas obras do autor a partir da declamação de seus poemas. A narrativa do guia 02 não se mostrou interessante para o grupo, pois grande parte estava disperso no ônibus mesmo enquanto o guia narrava histórias do poeta. O profissional demonstrou pouca habilidade de relacionamento com grupo e pouco dinamismo. Não se identificaram esforços do guia referentes à interpretação patrimonial, em nenhum nível, mesmo tendo visitado um museu (Museu da Abolição), lócus que demanda processos interpretativos para compreensão e melhor apreciação do lugar. Acredita-se que por isso, quando questionados, no grupo focal, quanto à experiência, as respostas tenham sido evasivas, não dando espaço para inferências

Puderam ser identificadas como funções latentes neste roteiro a inserção do turista no processo de comunicação pessoal e social interpretativo, possibilitado pela apresentação da peça teatral e declamação dos poemas de Solano Trindade sobre as lutas que os negros enfrentaram; os participantes se sensibilizaram com a encenação dos atores. A encenação possibilitou ainda a construção de sentidos e elaboração de significados passivos de interpretação e semiose, assim como, promoveu a interpretação das contingências por meio de uma leitura intertextual da cidade; ratifica-se, porém que isso foi permitido pelo envolvimento emocional dos turistas pela apresentação cênica dos atores e não às técnicas de guiamento.

Quanto à percepção vê-se, novamente, a presença do olhar, principalmente por meio da encenação, através da qual emergiu um "olhar social" (sujeito 21), complementado pelo sujeito 22 "[...] a questão social, além do benefício literário, traz um pouco da provocação do aspecto social ao relatar toda essa questão da cultura africana, como no Pátio de São Pedro vem com intolerância, vem reforçar no dia a dia a gente não calar [..] todo esse trabalho de hoje veio provocar a inquietação social [...]". A partir disso, a sensação que surge é de consciência social que deve ser propagada às novas gerações: "Como discutiu no pátio de São Pedro, a mentalidade das crianças, os pais levarem as crianças e tentar quebrar essa corrente [de preconceito]" (sujeito 22). Embora na questão sobre emoção não se tenha tido resposta, pode-se inferir com base em outros trechos que a emoção que marcou o roteiro foi a alteridade e a empatia, olhar a cultura e a realidade com os olhos do outro, colocar-se no lugar dele, para que daí o respeito possa emergir. Disso, portanto, os sujeitos pontuaram sentimentos como cumplicidade, solidariedade, esperança de melhores dias e respeito ao próximo.

\subsection{Circuito Afro}

O roteiro "Circuito Afro" foi inusitado, de acordo com a qualificação dada por um dos turistas no grupo focal, por ter fugido do habitual, despertando a curiosidade por meio da visitação a espaços pouco 
visitados turisticamente, como um Terreiro de Candomblé. Além deste, também se visitou a sede do Maracatu Nação Raízes de Pai Adão.

Quando pedidos para narrarem suas experiências, os turistas indicaram que o roteiro foi "[...] bem inusitado porque [foi a] uma parte do Recife que eu não conhecia [...]" (sujeito 23); a descoberta também foi fator importante na narrativa da experiência: "pra mim foi muito interessante porque eu passei a conhecer coisas... Assim, eu sabia que existia, mas eu nunca tinha tido experiência de poder ver com meus próprios olhos" (sujeito 24). No que concerne à expectativa dos turistas percebeu-se que elas foram atingidas e superadas, o que foi possível pela visitação ao terreiro do Pai Adão, onde os turistas obtiveram informações acerca da religião de matriz africana, o que causou uma desmistificação da cultura Afro, o "pra mim o ponto alto foi o terreiro de Pai Adão [...]" (sujeito 23).

Este foi o único dos roteiros nos qual os turistas apontaram ter tido uma experiência marcante, o que, mais uma vez, somente foi possível pela visitação ao terreiro: [...] ver aquela capela e ver o espaço deles do lado [vila onde moram os descendentes de Pai Adão], aquilo foi bem marcante pra mim" (sujeito 22); o sujeito 25 corrobora com isso e aponta que "o ponto forte pra mim foi o terreiro com o maracatu, o conjunto".

Frente a isto, houve interesse do grupo em adquirir conhecimento, transportando-o à temporalidade dos fatos narrados. Durante o guiamento também foi desvendado o misticismo das religiões de matriz africana, donde emergiu enriquecimento pessoal pelo aprofundamento sobre a cultura negra. O guia 01 demonstrou capacidade técnica no desempenho de sua função, com competência técnica e comportamental durante todo percurso.

No que se refere à interpretação, o profissional revelou o significado do signo de um dos atrativos visitados, a estátua do poeta Solano Trindade, quem está sobre uma alfaia (instrumento de percussão). No ilê (terreiro de candomblé) também se revelaram os signos ali presentes e os significados das imagens que existiam no terreiro de Pai Adão. Além disso, a narrativa do guia foi marcada pela ênfase dada à necessidade de conhecer, respeitar e valorizar a cultura negra como forma de diluição do preconceito.

Outras funções latentes identificadas foram a inserção do turista com relação à interação com a população local, podendo assim vivenciar a experiência de tocar os instrumentos do maracatu na comunidade visitada. A intertextualidade se deu nos espaços que continham os atrativos pela relação entre cultura, história e religiosidade.

Assim como nos demais roteiros, o olhar foi algo despertado nesta experiência, o que fica nítido na narração sobre a estátua de Solano Trindade "a gente passa por ali, vai no show da terça negra nem [percebia] a estátua [..]" (sujeito 23). Neste roteiro foi possível combinar a audição à visão durante a visitação, fato importante para sensibilizar os turistas quanto à relevância de reconhecer e valorizar a cultura negra. O sujeito 26 expõe a ideia de perda da identidade cultural de matriz africana quando diz "[...] então nós aqui somos os herdeiros e que também está se perdendo [a cultura negra], porque até o candomblé aqui está se extinguindo [...]" [sic].

Através da visitação, os turistas tiveram como forte percepção frente à intolerância religiosa contra o povo de terreiro: "[...] tal terreiro de candomblé que sofria perseguição [...]" (sujeito 22), "[...] esconder e camuflar isso [os ritos de candomblé] através de outra religião que era católica" (sujeito 23).

\subsection{Roteiro Jardim Botânico}

No roteiro "Jardim Botânico" constatou-se que o guia 04 não tinha habilidade para conduzir o grupo, o qual se manteve disperso. Da mesma forma, apresentou baixo desempenho técnico no exercício de sua função, uma vez que não aguardou que todos descessem do ônibus, para juntar o grupo para chegar no destino; tinha uma narrativa confusa e uma dicção que comprometeu o entendimento de seu discurso; não despertou a curiosidade e tampouco a satisfação pessoal dos turistas. O profissional utilizou frequentemente um caderno de apoio, usando uma 
linguagem pouco formal. Além disso, o guia mostrouse pouco ágil e pouco dinâmico. Apesar de ter feito um quiz no ônibus sobre conhecimentos gerais, não envolveu os turistas. O guia mostrou pouco conhecimento do processo interpretativo, uma vez que quanto a esta categoria, considerou-se apenas que ele revelou signos do lugar, ao passo em que foi narrado o uso medicinal de algumas plantas, o que despertou a curiosidade de alguns dos participantes. Nesse roteiro foi identificado apenas uma função latente: a inserção do turista no processo de comunicação pessoal e social, possibilitada pela revelação dos signos do lugar, que se deu pela identificação dos efeitos medicinais de algumas das mostra de flora.

Quanto aos turistas, estes afirmaram não terem tido suas expectativas superadas, também sinalizaram que não houve nenhuma experiência marcante durante a vivência do roteiro, assim como a fuga do senso comum também não foi registrada, pois havia uma expectativa de encontrar registros de flora diferentes das habituais.

\subsection{Roteiro Recife e Olinda}

No roteiro "Recife e Olinda" destacaram-se o Marco Zero da cidade de Recife e as esculturas de Francisco Brennand, foram apresentados também outros monumentos históricos que compõem o lugar. O guia 05 utilizou a bandeira de Pernambuco para reunir o grupo em alguns momentos oportunos, utilizou ainda a sinalização para a travessia segura dos turistas na faixa de pedestre (importantes técnicas de guiamento, negligenciada pelos outros guias); mostrou-se ágil para responder as perguntas feitas pelos turistas, donde demonstrou conhecimentos gerais e boa comunicação verbal. Apesar disso, o grupo manteve-se disperso em vários momentos, inclusive durante a narrativa do profissional, o que demonstrou o não despertar de interesse dos turistas, assim como, o não despertar de novas atitudes. No que tange à interpretação patrimonial, o guia revelou baixo conhecimento das técnicas necessárias, pois nenhum dos pontos observáveis referentes a esta categoria foi identificado. Tampouco foram identificadas as funções latentes referentes às duas categorias de análise.

Ao narrarem suas experiências, os turistas apontaram o desconhecimento sobre o significado de alguns dos pontos visitados, conforme pode ser observado: "a gente passa por aqui [Marco Zero] todo dia, mas não sabe o que significa" [...] (sujeito 32), já o sujeito 33 enfatiza o conhecimento quando diz que "[...] deu pra ter novos conhecimentos, não só pra hoje, mas pra vida toda", ao que o sujeito 34 complementa afirmando que o roteiro possibilitou "[...] a oportunidade de conhecer a história, os dados históricos, que o guia passou pra gente". Apesar disso, não foi possível identificar no discurso dos sujeitos sinais de superação das expectativas, mas o sujeito 35 aponta que sua expectativa foi alcançada. Corroborando com este dado, consequentemente, não houve marcas de que o roteiro tenha fomentado uma experiência marcante.

Quanto às sensações, o sentido atenuado foi a visão, possibilitado pelo olhar contemplativo à cidade de Olinda: "[...] aí a gente consegue contemplar a paisagem, a cultura e monumentos [...]" (sujeito 32), o que abriu espaço ao encantamento com a cidade: "Acho que de encantamento, né?" (sujeito 34); e, como consequência desse encantamento emerge o sentimento de pertencimento e de valorização da identidade: "[...] a gente passa aqui todo dia e não tem esse sentimento de 'isso é meu, eu faço parte disso', então quando a gente começa a conhecer, quando a gente tem a oportunidade de conhecer, a gente começa a se sentir parte [...]" (sujeito 34) e também: "Eu me senti, assim, mais orgulhosa de ser recifense, de ser cidadã recifense. Porque realmente a cidade, ela é de uma grande beleza, que a gente realmente não percebe" (sujeito 32). A partir disso, é possível inferir, ainda que não tenha sido mencionado explicitamente, que a emoção despertada com esta experiência é a afetividade para com a cidade. 


\section{Considerações finais}

Tendo descrito os critérios observados ao longo dos guiamentos nos roteiros do programa "olha! Recife" pode-se observar a grande incidência de funções manifestas em comparação às funções latentes, conforme pode ser observado nos quadros 02 e 03.

\section{Quadro 02: Ocorrência das funções manifestas nos roteiros realizados no programa "Olha! Recife"}

\begin{tabular}{|c|c|c|c|}
\hline Guiamento & Ocorrência & $\begin{array}{c}\text { Interpretação } \\
\text { patrimonial }\end{array}$ & Ocorrência \\
\hline $\begin{array}{l}\text { Prestação de } \\
\text { informações do } \\
\text { lugar visitado }\end{array}$ & 5 & $\begin{array}{l}\text { Revelação dos } \\
\text { significados dos } \\
\text { signos do lugar }\end{array}$ & 4 \\
\hline $\begin{array}{l}\text { Assessoramento ao } \\
\text { turista quando } \\
\text { necessário }\end{array}$ & * & $\begin{array}{l}\text { Provocação e } \\
\text { despertamento } \\
\text { das emoções } \\
\text { dos turistas }\end{array}$ & 1 \\
\hline $\begin{array}{l}\text { Habilidade em } \\
\text { relacionar-se bem } \\
\text { com as pessoas }\end{array}$ & 8 & $\begin{array}{l}\text { Estímulo à } \\
\text { curiosidade dos } \\
\text { turistas }\end{array}$ & 5 \\
\hline $\begin{array}{l}\text { Habilidade em } \\
\text { relacionar-se bem } \\
\text { com o grupo }\end{array}$ & 6 & $\begin{array}{l}\text { Entretenimento } \\
\text { dos turistas }\end{array}$ & 2 \\
\hline Agilidade & 7 & $\begin{array}{l}\text { Inspiração de } \\
\text { novas atitudes } \\
\text { no turista } \\
\end{array}$ & 2 \\
\hline Dinamismo & 3 & $\begin{array}{l}\text { Promoção de } \\
\text { experiências } \\
\text { marcantes }\end{array}$ & 2 \\
\hline $\begin{array}{l}\text { Aptidão em } \\
\text { solucionar } \\
\text { imprevisto }\end{array}$ & * & $\begin{array}{l}\text { Envolvimento da } \\
\text { população local } \\
\text { no processo } \\
\text { interpretativo }\end{array}$ & 1 \\
\hline $\begin{array}{l}\text { Domina os } \\
\text { princípios da } \\
\text { psicologia } \\
\text { interpessoal }\end{array}$ & 6 & $\begin{array}{l}\text { Estímulo à } \\
\text { compreensão e } \\
\text { apreciação do } \\
\text { destino }\end{array}$ & 5 \\
\hline $\begin{array}{l}\text { Conhecimento } \\
\text { técnico no } \\
\text { desempenho da } \\
\text { função }\end{array}$ & 5 & & \\
\hline $\begin{array}{l}\text { Demonstração de } \\
\text { conhecimentos } \\
\text { gerais }\end{array}$ & 7 & & \\
\hline $\begin{array}{l}\text { Boa comunicação } \\
\text { verbal }\end{array}$ & 7 & & \\
\hline $\begin{array}{l}\text { Boa comunicação } \\
\text { corporal }\end{array}$ & 7 & & \\
\hline $\begin{array}{l}\text { Clareza na } \\
\text { comunicação }\end{array}$ & 7 & & \\
\hline $\begin{array}{l}\text { Coerência na } \\
\text { narrativa }\end{array}$ & 7 & & \\
\hline $\begin{array}{l}\text { Induz ao interesse } \\
\text { no grupo a partir da } \\
\text { narrativa }\end{array}$ & 4 & & \\
\hline $\begin{array}{l}\text { Fala pausadamente } \\
\text { e varia a entonação } \\
\text { durante a narrativa }\end{array}$ & 7 & & \\
\hline
\end{tabular}

Com base nisso, é possível concluir que os guias de turismo apresentam competências técnicas e comportamentais dentro do que é esperado no contexto tradicional de roteiro turístico no que tange ao guiamento. Em relação à interpretação patrimonial, devido às múltiplas nuances que possui, foi necessário analisá-la com maior cautela; pois mesmo nos pontos com maior incidência (estímulo à curiosidade e à compreensão e apreciação dos atrativos) aconteceram em cerca de apenas $70 \%$ dos roteiros. No entanto, entende-se que as funções manifestas da interpretação patrimonial são essenciais para a elaboração de sentido sobre o destino visitado, pois é por meio dela que o guia poderá entre-lugarizar o turista no destino visitado através do despertamento das emoções, das experiências marcantes e a inspiração de novas atitudes, os quais foram pontos que tiveram baixa incidência.

Apesar disto, é importante ressaltar que mesmo nos roteiros em que o guia não realizou a interpretação patrimonial, a simples narrativa histórica do profissional foi suficiente para despertar no turista o sentimento de pertencimento (a exemplo do roteiro "Recife e Olinda"): "A gente as vezes no dia-a-dia não para pra observar o que está ali na frente e a gente fazendo essa excursão a gente meio que fica... vê de fora, né? E vai específico praquele lugar e aí você consegue contemplar a paisagem e esculturas, né? E monumentos... no caso aí de Olinda, as igrejas, que são coisas que a gente sai passando e nem presta a devida atenção" (sujeito 34).

Por meio deste relato é possível destacar alguns pontos relevantes: 1) a ratificação da ideia de turista cidadão, segundo apresentada por Gastal e Moesch (2007), como o morador local que se apropria dos fixos e fluxos de seu espaço; 2) por meio desta apropriação emerge o sentimento de pertencimento e identidade; 3) disso resulta a entre-lugarização do turista. 
Quadro 03: Ocorrência das funções latentes nos roteiros realizados no programa "Olha! Recife"

\begin{tabular}{|c|c|c|c|}
\hline Guiamento & Ocorrências & $\begin{array}{c}\text { Interpretação } \\
\text { patrimonial }\end{array}$ & Ocorrências \\
\hline $\begin{array}{l}\text { Apresentação } \\
\text { de uma visão } \\
\text { multidisciplinar } \\
\text { sobre a cidade }\end{array}$ & 1 & $\begin{array}{l}\text { Habilidade em } \\
\text { construir } \\
\text { sentidos e } \\
\text { elaboração de } \\
\text { significados } \\
\text { passivos de } \\
\text { interpretação } \\
\text { e semiose }\end{array}$ & 4 \\
\hline $\begin{array}{l}\text { Apresentação } \\
\text { de uma visão } \\
\text { multidisciplinar } \\
\text { sobre o } \\
\text { turismo }\end{array}$ & * & $\begin{array}{l}\text { Leitura e } \\
\text { transcrição da } \\
\text { linguagem da } \\
\text { cidade sem } \\
\text { metáforas }\end{array}$ & 1 \\
\hline $\begin{array}{c}\text { Compreensão } \\
\text { da cidade } \\
\text { como um texto } \\
\text { a ser } \\
\text { decifrado }\end{array}$ & * & & \\
\hline $\begin{array}{l}\text { Inserção do } \\
\text { turista no } \\
\text { processo de } \\
\text { comunicação } \\
\text { pessoal e } \\
\text { social }\end{array}$ & 6 & & \\
\hline $\begin{array}{c}\text { Possibilita a } \\
\text { interpretação } \\
\text { das } \\
\text { contingencias } \\
\text { intertextuais } \\
\end{array}$ & 3 & & \\
\hline $\begin{array}{l}\text { Mapeamento } \\
\text { cognitivo para } \\
\text { revelação das } \\
\text { "questões } \\
\text { ocultas" da } \\
\text { cidade }\end{array}$ & * & & \\
\hline $\begin{array}{l}\text { Promoção da } \\
\text { interpretação } \\
\text { do texto } \\
\text { urbano }\end{array}$ & * & & \\
\hline
\end{tabular}

A análise das funções latentes revela que no que se refere ao guiamento apenas a inserção do turista no processo de comunicação pessoal e social teve grande ocorrência. A interpretação das contingências intertextuais teve 4 ocorrências, enquanto que a apresentação de uma visão multidisciplinar sobre a cidade teve apenas 1 ocorrência, as demais não tiveram nenhuma ocorrência.

No que tange às funções latentes da interpretação patrimonial vê-se também a baixa ocorrência de habilidade em construir sentidos e elaboração de significados passíveis de interpretação e semiose, assim como de fazer uma leitura e transcrição da linguagem da cidade sem metáforas. Isso significa que tanto as técnicas de guiamento quanto à interpretação patrimonial precisam ser aperfeiçoadas para que se possam atender as demandas de um roteiro pós-moderno, que tem na experiência seu cerne; uma vez que estas funções estiveram presentes apenas em cerca de $26 \%$ dos roteiros.

Em comparação ao observado no roteiro "Recife e Olinda", expõe-se à uma análise mais acurada o "Circuito Afro", roteiro no qual houve revelação de signos, significados e interpretação do patrimônio por meio da participação ativa dos turistas pode-se perceber na narrativa dos turistas que estes tiveram uma experiência marcante, principalmente devido ao estranhamento frente à visitação a um espaço diferente do habitual.

Com base nisso é possível concluir que para que uma experiência marcante é possível quando vários elementos estão agrupados em um mesmo contexto de visitação turística: o estranhamento, a leitura do espaço por meio da interpretação dos signos observados, a entre-lugarização, por meio do despertar de emoções e sentimentos que vinculem o Sujeito àquele Lugar.

Por fim, é possível afirmar, com base nos roteiros analisados, que as competências técnicas e comportamentais do guia para o guiamento é dever, mas a interpretação, para despertar as emoções dos turistas, que seria o diferencial na atuação do guia ainda é uma competência que precisa ser mais bem trabalhada, de forma em que se gerem competências de leitura espacial sob as lentes da semiótica para que os guias sejam capazes de fomentar nos turistas a criação de mapas cognitivos, despertando-os para a sedução do lugar.

Respondendo, então, ao problema proposto neste estudo, pode-se afirmar o conhecimento das as demandas do Turismo hodierno se impõe como novas tarefas ao guia de turismo, no que se refere à geração de experiências marcantes, já que, conforme se pode observar no corpus desta análise é necessário vivenciar o roteiro com o comportamento de turista para que ele possa ser (entre-)lugarizado na cidade através do diálogo entre o Turista (leitor) e a cidade (autor) por meio da apropriação dos fatos históricos (texto) que compõem o Lugar. Quando o 
visitante não é um residente da cidade e, então, um Turista, vai haver o processo de Entre-Lugarização, para despertar a geração de sentidos e experiências.

A partir disso, pode-se concluir que 0 guiamento para roteiros turísticos pós-modernos, e como consequência, para o pós-turista, não se pode fragmentar ou descontextualizar o autor, o texto e o leitor. Os três precisam entrelaçar-se em um único contexto enunciativo que estará no lócus do sentido.

\section{Referências}

BALH, Miguel. Viagens e Roteiros Turísticos. Curitiba: Protexto, 2004.

BRASIL. Ministério do Turismo. Programa de Regionalização do Turismo: Roteiros do Brasil. Módulo Operacional 7. Brasília, 2007.

CASTELLS, Manuel. A sociedade em rede a era da informação: economia,sociedade e cultura $12^{\underline{a}}$ São Paulo: Paz e terra, 1999.

CASTROGIOVANNI, Antônio Carlos. O Lugar da Geografia no Entre-Lugar do Espaço Turístico: Uma Viagem Complexa. In: IX Colóquio Internacional de Geocrítica. Anais... UFRGS: Porto Alegre, 2007. Disponível em: <http://www.ub.edu/geocrit/9porto/castroge.htm >. Acessado em 09/10/2016.

CHIMENTI, Silvia; TAVARES, Adriana. M. Guia de Turismo: o profissional e a profissão. São Paulo: Editora Senac São Paulo, 2007.

CISNE, Rebecca. Roteiro turístico, tradição e superação: tempo, espaço, sujeito e (geo)tecnologia como categorias de análise. (dissertação de mestrado). Universidade de Caxias do Sul, Caxias do Sul-RS, 2010.

GAETA, Cecília. Turismo de experiência e novas demandas de formação profissional. In: PANOSSO NETTO, Alexandre; GAETA, Cecilia (orgs). Turismo de Experiência. São Paulo: Ed. Senac, 2010.

GASTAL, Susana. Turismo imagens e imaginários. São Paulo: Aleph, 2005.

GASTAL, Susana. Alegorias Urbanas: o passado como subterfúgios. Campinas, SP: Papirus, 2006. (Coleção Turismo).

GASTAL, Susana; MOESCH, Marutchska. Turismo, políticas públicas e cidadania. São Paulo: Aleph, 2007.

MACIEL, Turismo de experiência e o sentido da vida. In: PANOSSO NETTO, Alexandre;
GAETA, Cecilia (orgs). Turismo de Experiência. São Paulo: Ed. Senac, 2010.

MARCONI, Mariana; LAKATOS, Eva Maria. Fundamentos de metodologia científica. 7ed. São Paulo: Atlas, 2010.

PANOSSO NETTO, Alexandre. Experiência e turismo: uma união possível. PANOSSO NETTO, Alexandre; GAETA, Cecilia (orgs). Turismo de Experiência. São Paulo: Ed. Senac, 2010.

TAVARES, Adriana de Menezes. City tour. São Paulo: Aleph, 2002.

TRIGO, Luiz Gonzaga Godoi. A viagem como experiência significativa. In: PANOSSO NETTO, Alexandre; GAETA, Cecilia (orgs). Turismo de Experiência. São Paulo: Ed. Senac, 2010. 